\title{
Analytic hierarchy process (AHP) of mineral resources development and utilization efficiency
}

\author{
Junwei Zhao ${ }^{1}$, Heng Gan², Fuming Zheng ${ }^{2}$, Jianhua Chen ${ }^{2 a}$ \\ ${ }^{1}$ Zhengzhou Institute of Multipurpose Utilization of Mineral Resources, CAGS, Zhengzhou 450006, \\ China \\ ${ }^{2}$ School of Guangxi University, Nanning 530000, China \\ aganheng044@163.com
}

Keywords: analytic hierarchy process (AHP), mineral exploitation and utilization efficiency, decision evaluation

\begin{abstract}
The development and utilization efficiency of mineral resources is of great significance to the sustainable development of economy and the construction of a conservation-oriented and environment-friendly society. In this paper, we have studied the efficiency of development and utilization of six copper mines in China using analytic hierarchy process (AHP). The study provides a useful way to evaluate the efficiency of mineral resources development and utilization in the future.
\end{abstract}

\section{Introduction}

Analytic hierarchy process, introduced by an American operations researcher Saaty, is a systematized and hierarchical analytic technique combining of qualitative and quantitative analysis. Analytic hierarchy process was introduced to our country in $1982^{[1]}$. Solve the problem of decomposition into different components. First, according to the factors influence each other and affiliation to the hierarchical clustering combination. And then form a hierarchical and orderly hierarchical structure model, second, calculate the weight of each level of the elements relative to the upper level of a certain element. That is a hierarchical order, finally, by the weight value of the relative importance of each factor is calculated as the basis of the evaluation and selection scheme.

Analytic hierarchy process is applied in the field of Safety Science and Environmental Science. In the aspects of safety production science and technology the main applications include coal mine safety, hazardous chemicals, oil depot safety evaluation, urban disaster emergency response capacity and traffic safety assessment, etc. ${ }^{[2]}$ The application of environmental protection research mainly include water safety assessment, water quality indicators and environmental protection measures, ecological and environmental quality evaluation index system and aquatic wild animal protection area pollution sources, etc. Yong and Chen ${ }^{[3]}$ research on the safety of production resources based on AHP. The development and utilization of 8 kinds of main mineral resources in Guangxi were evaluated based on AHP by Wu Zhongxiong and Zhao Wenbin ${ }^{[4]}$. Mineral resources in Yunnan province economy was evaluated based on AHP by Xie Xianping, Zhao Zicheng ${ }^{[5]}$.

\section{Analytic hierarchy process}

\subsection{To construct judgment matrix.}

Table 1 Scale and the meaning of the judgment matrix

\begin{tabular}{|c|c|}
\hline Scaling & Meaning \\
\hline 1 & Bi is just as important as $\mathrm{Bj}$ \\
\hline 3 & Bi is a little bit more important than $\mathrm{Bj}$. \\
\hline 5 & Bi is more important than $\mathrm{Bj}$ \\
\hline 7 & Bi is much more important than $\mathrm{Bj}$ \\
\hline 9 & Bi is extremely important than $\mathrm{Bj}$ \\
& $4,6,8,2$ for the median value of the adjacent judgment \\
\hline
\end{tabular}


Which one is more important and how much importance of the two indicators are decided by the "1-9" scale to the importance of the assignment ${ }^{[6]}$. Any judgment matrix should be satisfied: bii $=1$; $\mathrm{Bij}=1 /$ bji $(\mathrm{I}, \mathrm{j}=1,2, \ldots, \mathrm{n})$

\subsection{Hierarchical order and consistency checking.}

Finding out the maximum characteristic root $\left(\lambda_{\max }\right)$ base on the judgment matrix. And then calculate the corresponding feature vector W. Equations are as follows:

$B W=\lambda_{\max } W$

where the weight of the $\mathrm{W}\left(\mathrm{W}_{2}, \mathrm{~W}_{1}, \ldots, \mathrm{W}_{\mathrm{n}}\right)$ is the corresponding to the relative importance of $\mathrm{n}$ elements. That is weight coefficient. In this paper, we use the method of "Sum product method" to calculate the weights. Calculation steps are as follows:

Judgment matrix of each column regularization:

$b_{i j}=\frac{b_{i j}}{\sum_{k=1}^{n} b_{k j}}, i, j=1,2, \ldots, n$

Each column of the judgment matrix after normalization is added by rows:

$\overline{W_{i}}=\sum^{n} \overline{b_{i j}}, i, j=1,2, \ldots, n$

The regularization of the vector $\bar{W}=\left[\overline{W_{1}}, \overline{W_{2}}, \ldots, \bar{W}_{2}\right]^{T}$ :

$W=\frac{\overline{W_{i}}}{\sum_{j=1}^{n} \bar{W}_{j}}, i=1,2, \ldots, n$

Calculating the biggest characteristic root of the judgment matrix (Max):

$\lambda_{\max }=\sum_{i=1}^{n} \frac{(A W)_{i}}{n W_{i}}$

In order to check the consistency of the judgment matrix, it is needed to calculate its consistency index CI. Definition:

$$
C I=\frac{\lambda_{\max }-n}{n-1}
$$

It is clear that when a full consistency between the judgment matrixes the CI values is zero.In order to check the consistency of the judgment matrix, the CI and the average random consistency index RI (as shown in table 2) need to be compared, defined as CR:

$$
C R=\frac{C I}{R I}
$$

Table 2 One to nine order matrix RI

\begin{tabular}{|c|c|c|c|c|c|c|c|c|c|}
\hline Order number $/ \mathrm{n}$ & 1 & 2 & 3 & 4 & 5 & 6 & 7 & 8 & 9 \\
\hline $\mathrm{RI}$ & 0.00 & 0.00 & 0.58 & 0.90 & 1.12 & 1.24 & 1.32 & 1.41 & 1.45 \\
\hline
\end{tabular}

When the CR is less than or equal to 0.10 , that A has satisfactory consistency; When $\mathrm{CR}>0.10$, you must re adjust the value of the elements in the A until the condition is met.

\section{The results and analysis}

\subsection{Construct hierarchical graph}

Measures for the national mineral resources development strategy and the specific requirements of the mineral resources evaluation, we construct the domestic six copper mining of the mineral resources development and utilization efficiency of hierarchical analysis model. As shown in figure 3. This model is divided into four layers. The Target layer(A)-Comprehensive evaluation of mining mineral resources development and utilization efficiency, in order to get the advantage of mineral resources. The Rule Layer B including the five aspects of mineral resources evaluation criteria. B1-5 mark of distinction mining reclaiming ratio, ore dressing recovery rate, comprehensive utilization, mine safety index and mine environmental impact index. The Rule Layer $\mathrm{C}$ including six aspects of the evaluation of mineral processing recovery rate. Scheme layer $p$ has a total of seven. With P1-7 tag. 
Based on the analytic hierarchy process (ahp) model, building the hierarchical structure according to the research of the information and data. Hierarchical structure diagram (Figure 1) as shown below:

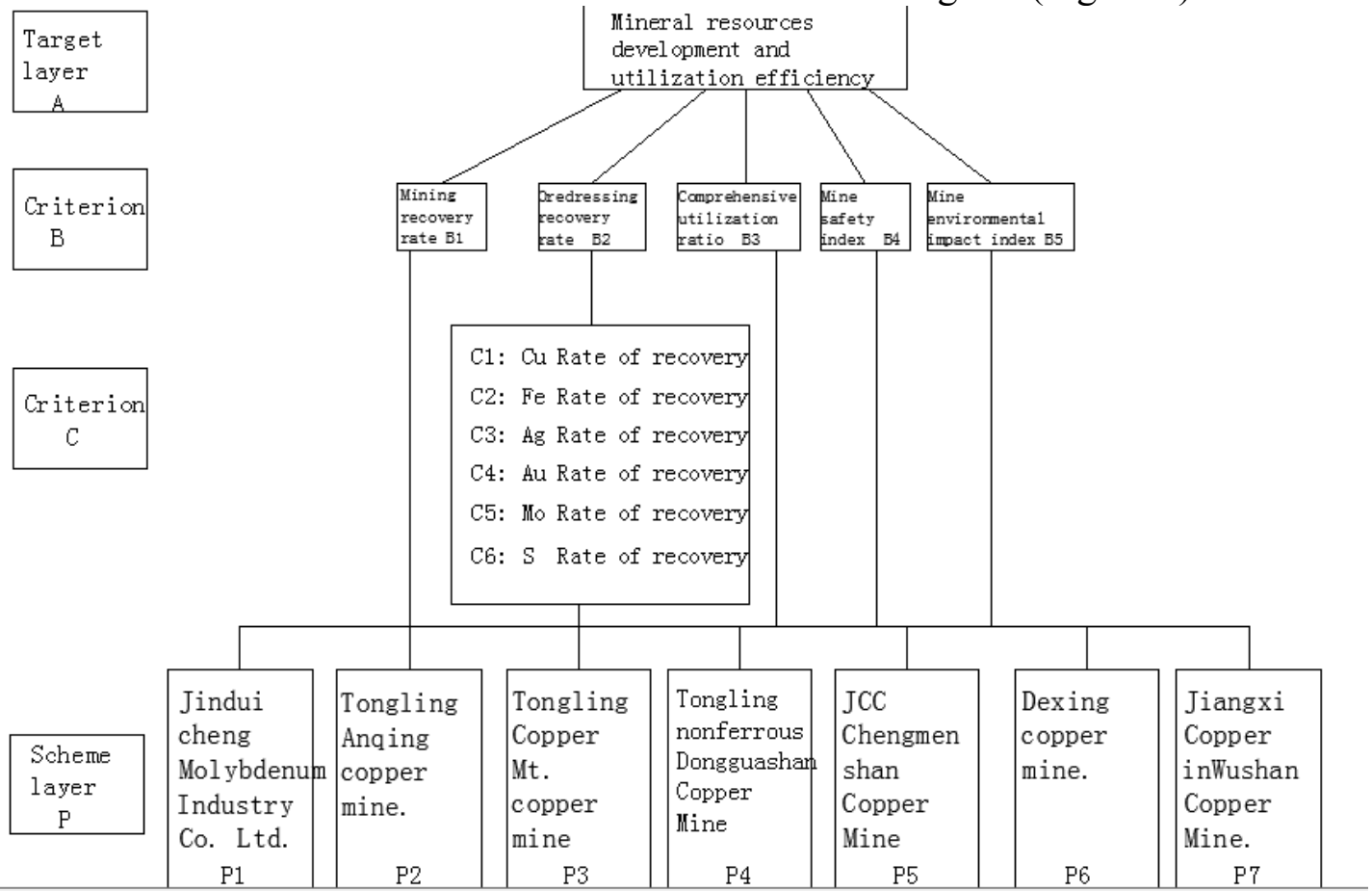

Figure 1. Considering security and environment influence the hierarchical structure of the graph

\subsection{Model solving}

The index system consists of one 5 level indicators, two 1 level indicators, three 6 level indicators, and four 7 level indicators. As shown in figure 3-1. According to the important degree of each factor of the index to construct judgment matrix. And then determine the weights of evaluation indexes. Last, the consistency check.

Table 3 general sort: A-P sort

\begin{tabular}{ccccccc}
\hline P & B1 & B2 & B 3 & B4 & B5 & \multirow{2}{*}{ Total Sort } \\
\cline { 2 - 5 } & 0.3696 & 0.3696 & 0.1705 & 0.0452 & 0.0452 & A \\
\hline P 1 & 0.297 & 0.072 & 0.1046 & 0.1429 & 0.1429 & 0.1671 \\
\hline P 2 & 0.047 & 0.0959 & 0.1753 & 0.1429 & 0.1429 & 0.0956 \\
\hline P 3 & 0.0512 & 0.1482 & 0.0334 & 0.1429 & 0.1429 & 0.0923 \\
\hline P 4 & 0.0599 & 0.1643 & 0.0447 & 0.1429 & 0.1429 & 0.1039 \\
\hline P 5 & 0.2049 & 0.0951 & 0.1753 & 0.1429 & 0.1429 & 0.1537 \\
\hline P 6 & 0.2049 & 0.3272 & 0.1942 & 0.1429 & 0.1429 & 0.2427 \\
\hline P 7 & 0.1350 & 0.097 & 0.2696 & 0.1429 & 0.1429 & 0.1446 \\
\hline
\end{tabular}

Consistency check: $\mathrm{CI}_{\mathrm{A}-\mathrm{P}}=0.026, \mathrm{CR}_{\mathrm{A}-\mathrm{P}}=0.02<0.1$

(1) From the B2 value it is known that in terms of ore dressing recovery, according to the mining of various mineral ore dressing recovery rate is calculated for each rank is the mine the total milling recovery of Dexing Copper Mine>Tongling Nonferrous Metals in Dongguashan Copper Mine $>$ Tongling Nonferrous Metals in Anqing Copper Mine $>$ Jiangxi Copper in Wushan Copper Mine $>$ Tongling nonferrous tongshan copper mine $>$ JCC Chengmenshan Copper Mine.

(2) From the A value it is known that order of the resources development and utilization efficiency is as follows: Dexing Copper Mine $>$ JCC Chengmenshan Copper Mine $>$ Jiangxi Copper in Wushan Copper Mine>Tongling Nonferrous Metals in Dongguashan Copper Mine>Tongling Nonferrous Metals in Anqing Copper Mine> Tongling nonferrous tongshan copper mine.

(3) From the point of hierarchy analysis results, it is found that Dexing Copper Mine is the number one both in the recovery rate of ores and the mineral resources development and utilization efficiency. Analytic hierarchy process well reflects the recovery of copper in Anqing copper mine. 


\section{Conclusion}

The efficiency of mineral resources development are important basis of evaluation of mine. This paper has chosen six domestic copper mine and using the principle of analytic hierarchy process to their utilization efficiency of mineral resources development in the decision making evaluation. The present work quantitatively evaluates the economic evaluation of mineral resources, and this method can provide a reference for the use of AHP to solve other problems.

\section{Reference}

[1] Liu Bao et al. Analytic hierarchy process planning tool [J]. Systems ngineering, 1984; 2: 23-30 (In China)

[2] Guo Jinyu, Zhang Zhongbin, Sun Qingyun. Application of analytic hierarchy process in safety science research [J]. Science and technology of safety production in china, 2008, 4(2): 69 73(In China)

[3] Yong Xueyan, Chen Jianhong. Research on mineral resources security evaluation based on AHP [J]. 2010(10) 31-5(In China)

[4] Wu Zhongxiong, Zhao Wenbin. The evaluation of the exploitation and utilization of mineral resources in Guangxi [J]. Chinese mining industry, 2006(12): 12 -0091-04(In China)

[5] Xie Xianping, Zhao Zicheng. Analytic hierarchy process of economic evaluation of mineral resources [J]. Journal of Kunming Institute of Technology, 1991(10): 16-5(In China)

[6] SaatyT.L. The Analytic Hierarchy Proeess. Me-Graw-Hill[J]. NewYork: 1980: 25-29. 